now considering whether the other scheduled unmanned flight could be dispensed with. Premature cut-off of propulsion firings has been attributed to overconservative programming of the on-board guidance computer and not to malfunction.

Thorough check-out of the various components of the lunar landing mission is essential, since there is considered to be no possibility of survival or reseue from an accident on or near the Moon. Dr George Mueller, director of the manned spaceflight programme, recently made clear that on the Moon there will be a $36 \mathrm{~h}$ oxygen supply for the two astronauts, not a large margin on the projected 22 hour stay. No rescue provisions are being made. It would take a month at least to get a relief party out there, Dr Mueller pointed out.

Nevertheless NASA has recently appointed a Safety Director whose job it will be to look into the problems of orbital rescue as well as the more conventional aspects of spacecraft and range safety. In his mid-40s, Bob P. Helgeson has had experience in atomic energy as well as with the X-15 hypersonic research aircraft programme.

\section{Hovercraft Launched}

THE largest hovercraft in the world took to the water this week for its first trial. Built by the British Hovercraft Corporation at Cowes, the hovercraft is called the SRN 4, or, more grandly, the first of the Mountbatten class. It will be used as a cross-Channel ferry by British Rail and by the Swedish firm Hoverlloyd, carrying 254 passengers and 30 cars, or 600 passengers. Despite unpleasant weather conditions for the launching, the four-engined craft got away successfully, and, it seems, comparatively quietly, although so long as hovercraft are propelled by large aero engines driving propellers they are never likely to compete for quietness with muffled oars. The launching is a great moment for those who have supported the development of hovercraft in Britain, and for their inventor, Mr Christopher Cockerell, who was there to see it happen.

Sadly, it is not quite so cheerful a moment for the

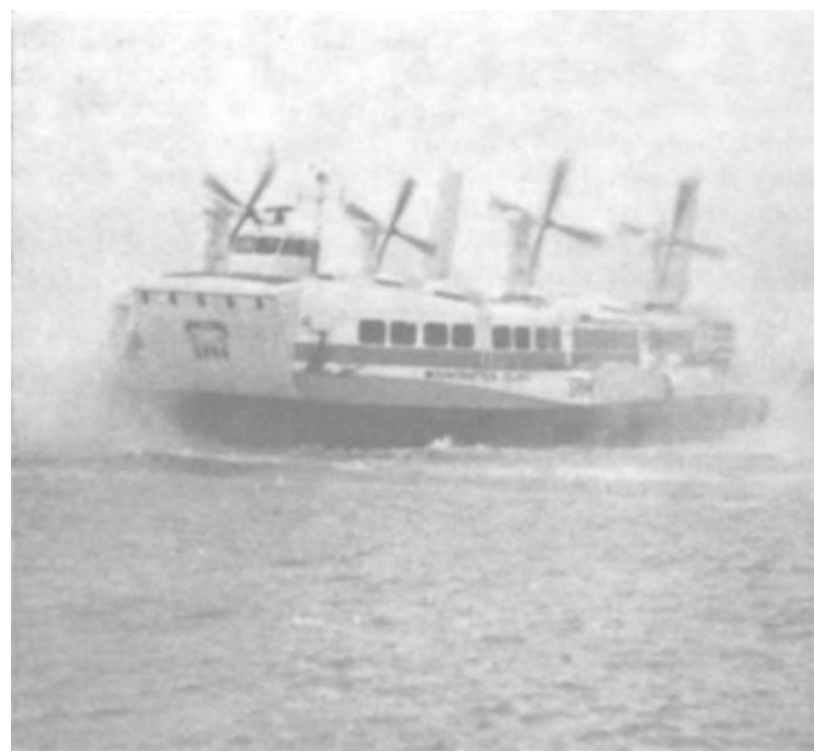

The SRN4 hovercraft on its first trial. design staff of the British Hovercraft Corporation. The company announced this week that 40 members of the design staff working at Hitchen will be laid off over the next 2 months. The reason for this, the company says, is twofold. At the end of 1967, a number of projects which the company had hoped to start work on at Hitchen and Cowes failed to materialize. Coupled with the cuts which the Ministry of Defence has made, this has meant that design staff will have to go. Some, it is hoped, will be found work with Westland Aircraft (one of the two major shareholders in BHC). At Cowes, there should be sufficient work to sustain the design team.

\section{School Mathematics}

THE report of the director of the School Mathematics Project for 1966-67 has a cheerful tale to tell about the acceptance of the new courses as qualifications for entry to universities. Dr Bryan Thwaites says that "with only one or two exceptions" all university departments of mathematics are prepared to accept as candidates for entry students with a pass in the Advanced level examination in what is called "SMP Mathematics". Even so, it seems, suspicions persist in the schools that a double dose of SMP is likely to be a safer means of being accepted than a single dose, and these suspicions seem to be borne out by the reaction of some of the universities to the new courses. Dr Thwaites says that "at least some university departments are going against the spirit of their formal acceptance ..." by asking extra of intending students. It remains of course to be seen whether Dr Thwaites's exhortation will bring backsliding universities to heel.

To judge from what the report says, the publication programme is now virtually complete. This means that courses are available for students between 11 and 18 . One innovation, however, is that the School Mathematics Project has turned itself into a trust which will presumably be able to superintend the further development of the teaching materials now available.

\section{Undivided Seconds}

\section{from our Oxford Correspondent}

RATHER surprisingly, Congregation at Oxford has reversed its decision to divide the second class degree into upper and lower parts, a proposal accepted last term by 101 votes to 99 (see Nature, 216, 631; 1967). This term's debate, on an opposition amendment that the division should be indefinitely postponed, was very much better attended. The debate, however, seemed somewhat confused, with members finding it hard to distinguish the germane from the irrelevant. There was a certain amount of doubt whether the original proposal had been to enlarge the second class as well as divide it, or merely to divide it-the two measures having rather different effects. The final vote for the amendment was 171-121, so that for some time at any rate Oxford will be making no official distinction between types of second class. What will happen, doubtless, is that fewer Thirds will be awarded, and that the Fourth Class will cease in practice to exist. So Oxford will be aligning its degree classes with those of other British universities while avoiding the difficulties of subdividing the second class candidates, most of whom would be on the borderline of 